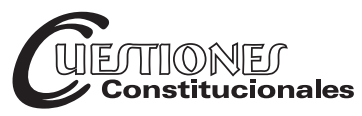

Revista Mexicana de Derecho Constitucional Núm. 41, julio-diciembre 2019

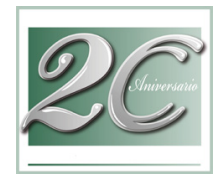

\title{
Aproximación al control externo y su relación con la rendición de cuentas
}

\author{
Approach to the external control and its relation \\ to accountability
}

\section{Olga Susana MÉndeZ ARELlano*}

RESUMEN: En el artículo se hace referencia a los sistemas de control de los Estados democráticos, que se basan en el principio de la división de poderes y en la existencia de controles recíprocos. El Poder Legislativo, específicamente la Cámara de Diputados, cuenta con facultades constitucionales para ejercer un control externo sobre cualquier entidad, persona física o moral, pública o privada, que haya captado, recaudado, administrado, manejado o ejercido recursos públicos federales, lo cual resulta fundamental para evaluar la gestión gubernamental. El control que ejerce el Poder Legislativo sobre el Ejecutivo, a través de la fiscalización del gasto público tiene íntima relación con la rendición de cuentas y son elementos fundamentales de las democracias.

Palabras clave: Fiscalización, combate a la corrupción, responsabilidades, rendición de cuentas.
ABSTRACT: The article refers to the control systems of democratic states are based on the principle of the separation of powers and the existence of reciprocal controls. The Legislative Power, specifically the Chamber of Deputies, has constitutional faculties to exercise external control over any entity, physical or moral person, public or private that has received, collected, managed or exercised federal public resources, which is essential, to evaluate the government management. The control exercised by the Legislative Power over the Executive, through the control of public spending is closely related to accountability and are fundamental elements of democracies.

Keywords: Oversight, anti-corruption, public responsability, accountability.

* Doctoranda en la Escuela Internacional de Doctorado de la Universidad Nacional de Educación a Distancia (EIDUNED), España; https://orcid.org/0000-0002-8247-2823; susanamendezarellano@yahoo.com.mx. 
SUMARIO: I. Introducción. II. Fundamento constitucional. III. Control parlamentario. IV. Control externo. V. La rendición de cuentas. VI. Reflexiones finales. VII. Bibliografia.

\section{INTRODUCCIÓN}

Los sistemas actuales de control de los Estados democráticos sociales de derecho se basan en el principio de la división de poderes y en los balances y contrapesos que deben existir en el ejercicio de las funciones de poder. El Poder Legislativo es un contrapeso del Poder Ejecutivo y a través del control externo se constituye como vigilante del ejercicio del gasto público; es decir, se le atribuye la fiscalización del cumplimiento de los programas contenidos en el presupuesto.

Una de las mayores preocupaciones de los ciudadanos frente al gobierno es que se ejerza debidamente el gasto público, toda vez que el uso que se haga del dinero impacta en el nivel de vida de la población. Bajo esa perspectiva, la supervisión del ejercicio del gasto público se inscribe en la racionalización de la responsabilidad gubernamental y fortalece el control parlamentario sobre el origen y destino de los recursos públicos.

Un eficiente control del ejercicio del gasto público a través de la fiscalización superior y el apego a los principios de rendición de cuentas son elementos fundamentales de las democracias, pues su observancia permite elevar la credibilidad social sobre las instituciones. Actualmente observamos que existe una percepción de la población de que la actividad gubernamental es corrupta y que las conductas de los servidores públicos no se sancionan. Es por ello que las entidades de fiscalización desempeñan una función determinante en la lucha contra la corrupción, y para coadyuvar a que el gobierno utilice de manera eficiente los recursos públicos.

En México, existe una amplia estructura de control y supervisión, tanto al interior como al exterior de los distintos órganos que desempeñan funciones de gobierno. La Auditoría Superior de la Federación, la Secretaría de la Función Pública, las contralorías de las entidades federativas, las entidades de fiscalización superior locales, las contralorías municipales y las contralorías internas de los órganos constitucionalmente autónomos vigilan permanentemente el desempeño de los entes públicos.

El control resulta fundamental para evaluar la gestión gubernamental y el uso de los recursos públicos, tan es así que se ha integrado el sistema 
nacional de fiscalización, ante la necesidad de formar un frente común en todos los órdenes de gobierno y desde todos los ámbitos de análisis para lograr una mejor rendición de cuentas, lo cual derivó, en mayo de 2015, en la aprobación de las reformas constitucionales que dan origen al sistema nacional anticorrupción.

De ahí la importancia de realizar un análisis del control externo que ejerce el Poder Legislativo sobre el Ejecutivo, el Judicial, así como de los organismos constitucionalmente autónomos, ${ }^{1}$ el cual presenta un desarrollo jurídico consolidado a través de figuras como la rendición de cuentas y la fiscalización que realiza la Auditoría Superior de la Federación, que es el órgano técnico de fiscalización de la Cámara de Diputados del Congreso de la Unión, y que fiscaliza a todo ente público, persona física o moral, pública o privada, que haya captado, recaudado, administrado, manejado, ejercido, cobrado o recibido recursos públicos federales o participaciones federales.

\section{FUNDAMENTO CONSTITUCIONAL}

El control es un instrumento indispensable para el equilibrio de los poderes y encuentra su fundamento en la Constitución, en la cual se limita a cada uno de los poderes y se establecen controles recíprocos; Aragón sostiene que "No es concebible, pues, la Constitución como norma, y menos la Constitución del Estado social y democrático de derecho, si no descansa en la existencia y efectividad de los controles". ${ }^{2}$

En México, la referencia al control la encontramos en el artículo 73, fracción XXIV, de la Constitución Política de los Estados Unidos Mexicanos, que consagra las facultades del Congreso para expedir las leyes que regulen la organización y facultades de la Auditoría Superior de la Federación y las demás que normen la gestión, control y evaluación de los poderes de la unión y de los entes públicos federales, así como para expedir la ley general que

\footnotetext{
1 Los organismos con autonomía constitucional no dependen jerárquicamente ni se encuentran subordinados a los poderes tradicionales, cuentan con facultades para determinar y proponer su presupuesto, y se encuentran obligados a rendir cuentas del ejercicio del presupuesto y del cumplimiento de sus programas.

2 Aragón, Manuel, Constitución, democracia y control, México, UNAM, Instituto de Investigaciones Jurídicas, 2002, p. 102, disponible en: https://archivos.juridicas.unam. $m x / w w w / b j v / l i b r o s / 1 / 288 / 1$.pdf (última fecha de consulta: 19 de octubre de 2018).
} 
establezca las bases de coordinación del sistema nacional anticorrupción a que se refiere el artículo 113 de la propia Constitución.

En el artículo 74, fracción II, se establece como facultad exclusiva de la Cámara de Diputados la de coordinar y evaluar, sin perjuicio de su autonomía técnica y de gestión, el desempeño de las funciones de la Auditoría Superior de la Federación, en los términos que disponga la ley. Para ello cuenta con la Unidad de Evaluación y Control, que es una unidad administrativa de la Cámara de Diputados que depende de la Comisión de Vigilancia de la Auditoría Superior de la Federación, la cual vigila el estricto cumplimiento de sus funciones, es decir, fiscaliza al fiscalizador mediante la práctica de auditorías para garantizar que su facultad exclusiva de revisar la cuenta pública se realice de manera adecuada, y no se aparte del objeto de la revisión de la cuenta pública de evaluar los resultados de la gestión financiera, comprobar si se ha ajustado a los criterios señalados en el presupuesto y verificar el cumplimiento de los objetivos contenidos en los programas.

En la fracción VI del citado precepto consagra como facultad de la Cámara de Diputados la de aprobar anualmente el Presupuesto de Egresos de la Federación, previo examen, discusión y, en su caso, modificación del proyecto enviado por el Ejecutivo Federal, una vez aprobadas las contribuciones que, a su juicio, deben decretarse para cubrirlo. Adicionalmente, cuenta con facultades para autorizar en dicho presupuesto las erogaciones plurianuales para aquellos proyectos de inversión en infraestructura que se determinen conforme a lo dispuesto en la ley reglamentaria.

En relación con el control externo, la Cámara de Diputados cuenta con facultades para revisar la cuenta pública del año anterior, que tiene por objeto evaluar los resultados de la gestión financiera, comprobar si se ha ajustado a los criterios señalados por el Presupuesto y verificar el cumplimiento de los objetivos contenidos en los programas.

La revisión de la Cuenta Pública se realiza a través de la Auditoría Superior de la Federación, que cuenta con facultades para determinar las responsabilidades cuando derivado del examen que realice aparezcan discrepancias entre las cantidades correspondientes a los ingresos o a los egresos, en relación con los conceptos y las partidas respectivas, o no existiera exactitud o justificación en los ingresos obtenidos o en los gastos realizados. En el caso de la revisión sobre el cumplimiento de los objetivos de los programas, puede emitir las recomendaciones para la mejora en el desempeño de los mismos, en los términos de la Ley. Dicha facultad se contiene en la fracción VI del citado artículo 74 constitucional. 
Otra facultad exclusiva con que cuenta la Cámara de Diputados es la relativa a declarar si hay o no lugar a proceder penalmente contra diputados y senadores del Congreso de la Unión, los ministros de la Suprema Corte de Justicia de la Nación, los magistrados de la Sala Superior del Tribunal Electoral, los consejeros de la Judicatura Federal, los secretarios de despacho, el fiscal general de la República, así como el consejero presidente y los consejeros electorales del Consejo General del Instituto Nacional Electoral, por la comisión de delitos durante el tiempo de su encargo, en los términos del artículo 111 de la Constitución, así como conocer de las imputaciones que se les hagan y fungir como órgano de acusación en los juicios políticos que contra éstos se instauren.

Por último, en la fracción VIII del artículo 74 se establecen las facultades exclusivas de la Cámara de Diputados para designar, por el voto de las dos terceras partes de sus miembros presentes, a los titulares de los órganos internos de control de los organismos con autonomía reconocida en la Constitución que ejerzan recursos del presupuesto de egresos de la Federación. Dicha facultad se incorporó en la reforma que se publicó en el Diario Oficial de la Federación el 27 de mayo de 2015, debido a que se cuestionaba la independencia de los contralores internos de los organismos autónomos, al ser nombrados por los titulares, y se encontraban jerárquicamente subordinados a éstos, lo cual restaba credibilidad y objetividad a su actuación.

En materia de control es trascedente el carácter de independencia de los titulares de los órganos internos de control, ya que cuando existe dependencia o sometimiento del titular, las irregularidades no se plantean objetivamente o los niveles de responsabilidad guardan una gran discrecionalidad, ya que se encuentran en un nivel inferior.

El artículo 79 de nuestra norma fundamental otorga a la Auditoría Superior de la Federación de la Cámara de Diputados, autonomía técnica y de gestión en el ejercicio de sus atribuciones y para decidir sobre su organización interna, funcionamiento y resoluciones, en los términos que disponga la ley. Establece que la función de fiscalización será ejercida conforme a los principios de legalidad, definitividad, imparcialidad y confiabilidad. Dicho órgano técnico tiene a su cargo la fiscalización en forma posterior de los ingresos, egresos y deuda; las garantías que, en su caso, otorgue el gobierno federal respecto a empréstitos de los estados y municipios; el manejo, la custodia y la aplicación de fondos y recursos de los poderes de la unión y de los entes públicos federales, así como realizar auditorías 
sobre el desempeño ${ }^{3}$ en el cumplimiento de los objetivos contenidos en los programas federales, a través de los informes que rinda. También fiscaliza directamente los recursos federales que administren o ejerzan las entidades federativas, los municipios y las demarcaciones territoriales de la Ciudad de México y en coordinación con las entidades locales de fiscalización o de manera directa, las participaciones federales.

En el caso de los estados y los municipios cuyos empréstitos cuenten con la garantía de la Federación, fiscaliza el destino y ejercicio de los recursos correspondientes que hayan realizado los gobiernos locales. Asimismo, los recursos federales que se destinen y se ejerzan por cualquier entidad, persona física o moral, pública o privada, y los transferidos a fideicomisos, fondos y mandatos, públicos o privados, o cualquier otra figura jurídica, de conformidad con los procedimientos establecidos en las leyes y sin perjuicio de la competencia de otras autoridades y de los derechos de los usuarios del sistema financiero.

Es de hacer notar que la corrupción ha generado entre la población una percepción de impunidad, y en general la población muestra desconfianza en las instituciones. La fiscalización superior es un instrumento indispensable para propiciar su combate y lograr que el gasto público se programe y ejerza con economía, eficiencia y eficacia.

El presente análisis pretende destacar que la rendición de cuentas y el control externo son elementos necesarios que contribuyen a un debido ejercicio del gasto público y a combatir la corrupción. No es objeto de la presente investigación el tema de la corrupción; sin embargo, en los resultados de la revisión a la cuenta pública del gobierno federal que efectúa la Auditoría Superior de la Federación invariablemente se detectan observaciones relacionadas con posibles hechos de corrupción de los servidores públicos y particulares con ellos relacionados. Por ello, se realiza una breve reflexión sobre el tema.

Diversas investigaciones y análisis realizados en materia de prevención de la corrupción, tanto nacionales como internacionales, dejan claro que

3 Las auditorías al desempeño consisten en el examen objetivo, sistemático, multidisciplinario, propositivo, organizado y comparativo, tanto de las actividades gubernamentales enfocadas a la ejecución de una política pública general, sectorial o regional, como de aquellas inherentes al funcionamiento de los entes públicos federales, a nivel institucional, de programa, proyecto o unidad administrativa. Miden el impacto social de la gestión pública y comparan lo propuesto por las políticas públicas con lo alcanzado realmente. 
la corrupción aleja la inversión, amenaza al medio ambiente, disminuye significativamente la productividad, e impide que millones de personas reciban bienes y servicios de calidad en esferas tan relevantes como el derecho a la alimentación, la justicia, la salud, la vivienda o la educación, entre muchos otros. ${ }^{4}$ La corrupción es un fenómeno mundial atribuido a diversas causas, a pesar de que no es exclusivo del servicio público, pues sus efectos se presentan también en el ámbito privado; uno de los que mayor atención representa es el que involucra a las autoridades y los recursos públicos. Transparencia Internacional ${ }^{5}$ ha insistido en sus diversos informes que los gobiernos deben incorporar acciones contra la corrupción en todas las decisiones públicas; entre las prioridades están normas más efectivas sobre financiamiento político, una mayor transparencia de la contratación y el gasto público, y mayor rendición de cuentas de organismos públicos a la población.

Transparencia Internacional promueve medidas contra la corrupción política en el ámbito internacional, y desde 1995 elabora el Índice de Percepción de la Corrupción, el cual es el principal indicador mundial de corrupción en el sector público. El índice ofrece resultados sobre el grado relativo de corrupción por países de todo el mundo y considera una escala de 0 (percepción de altos niveles de corrupción) a 100 (percepción de bajos niveles de corrupción).

En 2012, los países que obtuvieron más puntuación fueron Dinamarca, Finlandia y Nueva Zelanda con 90 puntos, ocupando el lugar número uno de los países con menor percepción de corrupción; en tanto que Somalia ocupó el lugar 176, al obtener sólo 12 puntos. México recibió una puntuación de 34, que lo ubica en la posición 105, muy por debajo de sus principales socios comerciales, Canadá y Estados Unidos, que se encontraron en la posición número 9 y 19 , respectivamente. ${ }^{6}$

4 Estudio sobre las estrategias para enfrentar la corrupción, establecidas en las instituciones del sector público federal, México, Auditoría Superior de la Federación, diciembre de 2016, consultado el 07 de febrero de 2019, disponible en: https://www.asf. gob.mx/Trans/Informes/IR2014i/Documentos/Auditorias/2014_1642_a.pdf.

5 Transparency International (TI) es una organización internacional no gubernamental, no partidista, y sin fines de lucro, dedicada a combatir la corrupción a nivel nacional e internacional. Fue fundada en 1993 y ha sido reconocida ampliamente por colocar la lucha anticorrupción en la agenda global.

6 Índice de percepción de la corrupción 2012, Alemania, Transparencia Internacional, 2013, disponible en: https://www.transparency.org/research/cpi/overview (consultado el 11 de febrero de 2019). 
En 2013, Dinamarca y Nueva Zelanda se ubicaron en la posición número uno al obtener 91 puntos de 100. México ocupó la posición 106 con 34 puntos; en tanto que los países que obtuvieron el índice más alto de corrupción fueron Afganistán, Corea del Norte y Somalia con sólo 8 puntos. ${ }^{7}$

Dinamarca se situó en la primera posición en 2014, con una puntuación de 92, mientras que Corea del Norte y Somalia compartieron el último lugar, con apenas 8 puntos. México se ubicó en el lugar 103 de 175 países, con una puntuación de 35/100; mientras que Corea del Norte y Somalia fueron percibidos como los más corruptos. México compartió ubicación en la tabla con Bolivia, Moldovia y Níger; en América Latina, México se ubicó en el lugar número 20 de 30 países, con posición por debajo de Chile y Brasil. ${ }^{8}$ Además, se ubicó en la última posición (34/34) entre los países que integran la Organización para la Cooperación y el Desarrollo Económicos (OCDE), que es un organismo internacional de carácter intergubernamental del que forman parte 34 países. ${ }^{9}$

En 2015, más de dos tercios de los 167 países incluidos en el Índice de Percepción de la Corrupción obtuvieron una puntuación inferior a 50, en una escala de 0 (percepción de altos niveles de corrupción) a 100 (percepción de bajos niveles de corrupción). Dinamarca se situó en la primera posición con una puntuación de 91, seguida de Finlandia con 90, mientras que Corea del Norte y Somalia compartieron el último lugar, con apenas 8 puntos. México se ubicó en el lugar 95 de 168 países, con una puntuación de 35/100. México compartió ubicación en la tabla con Armenia, Filipinas y Malí. ${ }^{10}$

Durante 2016, Transparencia Internacional observó que en todo el mundo la corrupción sistémica y la desigualdad social se refuerzan recíprocamente, y esto provoca decepción en la gente hacia su clase política y es un contexto

7 Índice de percepción de la corrupción 2013, Alemania, Transparencia Internacional, 2014, disponible en: https://www.transparency.org/research/cpi/overview (consultado el 12 de febrero de 2019).

8 Índice de percepción de la corrupción 2014, Alemania, Transparencia Internacional, 2015, disponible en: https://www.transparency.org/research/cpi/overview (consultado el 12 de febrero de 2019).

9 Fundada en 1961, la Organización para la Cooperación y el Desarrollo Económicos (OCDE) agrupa actualmente a 36 países miembros y su misión es promover políticas que mejoren el bienestar económico y social de las personas alrededor del mundo.

10 Índice de percepción de la corrupción 2015, Alemania, Transparencia Internacional, 2016, disponible en: https://www.transparency.org/research/cpi/overview (consultado el 12 de febrero de 2019). 
propicio para que se impongan los políticos populistas. ${ }^{11}$ En 2016, México se ubicó en el lugar 123 de 176 países con una puntuación de 30/100. Los países mejor evaluados fueron Dinamarca y Nueva Zelanda con 90 puntos, seguidas de Finlandia con 89 y Suecia con 88. Estos países comparten características de gobierno abierto, libertad de prensa, libertades civiles y sistemas judiciales independientes. Por décimo año consecutivo, Somalia obtuvo los peores resultados del índice, con apenas 10 puntos; Sudán del Sur se ubicó en el penúltimo puesto, con una puntuación de 11, seguido por Corea del Norte (12) y Siria (13). Los países en el extremo inferior del índice se distinguen por una impunidad generalizada de la corrupción, gobernabilidad deficiente e instituciones frágiles. México siguió ocupando la última posición (34/34) entre los países que integran la OCDE.

En 2017, Nueva Zelanda y Dinamarca ocuparon el primer lugar con puntuaciones de 89 y 88, respectivamente. Siria, Sudán del Sur y Somalia tienen las puntuaciones más bajas con 14, 12 y 9, respectivamente. México se ubicó en el lugar 136 de 180 países con una puntuación de 29/100. ${ }^{12}$

Los resultados del Índice de Percepción de la Corrupción muestran que de 2012 a 2017, México no mostró ninguna mejoría en la percepción internacional. Por el contrario, tan sólo de 2015 a 2017, perdió 6 puntos, lo cual tiene impacto en la economía nacional.

Considerando los resultados negativos, resulta imprescindible la actuación eficiente de la Auditoría Superior de la Federación, que al detectar irregularidades deberá promover acciones que permitan eliminar prácticas y procedimientos que propicien la corrupción, corregir los desvíos, modificar las políticas y sancionar a los responsables, y con ello contribuir al combate a la corrupción.

Las reformas constitucionales de mayo de 2015 establecieron la creación del sistema nacional anticorrupción, que tiene como fines centrales la prevención, detección y combate a la corrupción. Dicho sistema agrupa a las instituciones encargadas de combatir a la corrupción en un mismo comité, con el objetivo de que actúen de manera coordinada y alineados bajo una política nacional anticorrupción. Su objetivo último será poner fin a

11 Índice de percepción de la corrupción 2016, Alemania, Transparencia Internacional, 2017, disponible en: https://www.transparency.org/research/cpi/overview (consultado el 12 de febrero de 2019).

12 Índice de percepción de la corrupción 2017, Alemania, Transparencia Internacional, 2018, disponible en: https://www.transparency.org/research/cpi/overview (consultado el 12 de febrero de 2019). 
la creciente impunidad que impera en nuestro país. Sin embargo, no basta con realizar reformas legales contra la corrupción. Se requieren reformas sistémicas que contrarresten el creciente desequilibrio social, dar participación a los ciudadanos, sancionar las irregularidades para poner freno a la impunidad generalizada, así como fomentar la cultura de la denuncia.

Adicionalmente, debe considerarse que el eje rector de las políticas públicas en México es el desarrollo nacional; de ahí que las instituciones gubernamentales están llamadas a que su actuación, ya sea mediante la producción de bienes y la prestación de servicios públicos, genere condiciones de bienestar social. Para lograrlo, es ineludible, entre otras cosas, ejecutar una adecuada programación, seguimiento y control de los recursos que impulsen el cumplimiento de los programas; promuevan la rendición de cuentas y el combate a la corrupción, y garanticen el mejoramiento continuo de la actividad gubernamental, en lo cual toma relevancia el control externo. Con lo anterior, también se cumplen las demandas ciudadanas de conocer en qué y cómo se gastan los recursos públicos, y los resultados de la evaluación al desempeño de la administración pública en los tres órdenes de gobierno, y en este aspecto retoma importancia el control que ejerce el Poder Legislativo respecto de los actos del Ejecutivo, del Judicial, así como de los organismos con autonomía reconocida en la Constitución. Por ello, considerando la importancia del control externo y el interés general por fortalecer el proceso de rendición de cuentas, es necesario realizar un análisis que precise doctrinalmente su concepto y alcances.

\section{CONTROL PARLAMENTARIO}

Lanz Cárdenas señala "que los controles del Estado se clasifican, en principio, en razón de cada uno de los poderes y de sus funciones propias, a saber: control legislativo, control administrativo y control judicial o jurisdiccional". ${ }^{13}$

La separación de poderes se encuentra íntimamente relacionada al orden constitucional, que pone límites a sus atribuciones para evitar abusos. Montesquieu realizó una gran aportación al constitucionalismo con su teoría de la división de poderes al diseñar el esquema tripartito del poder

13 Lanz Cárdenas, José Trinidad, La contraloría y el control interno en México, 2a. ed., México, Secretaría de la Contraloría General de la Federación-Fondo de Cultura Económica, 1993, p. 468. 
(legislativo, ejecutivo y judicial), buscando el control y sometimiento del Ejecutivo a la ley. Garita Alonso destaca la importancia de crear mecanismos al interior del propio Estado, que mantengan a sus diferentes órganos dentro de esferas de competencia, en un marco de colaboración, evitando que unos abusen de otros, en detrimento de la libertad y los derechos de la población. ${ }^{14}$ Lo expuesto por Garita guarda íntima relación con el control externo; es decir, el control que ejerce el Poder Legislativo sobre el Ejecutivo respecto del ejercicio del gasto, en virtud de que si el Ejecutivo no administra el presupuesto debidamente, afecta los derechos de la población, debido a que gran parte del presupuesto se destina a programas sociales o a obras públicas que de no ejecutarse correctamente impactan negativamente en el nivel de vida de la población.

Es de suma importancia la forma en que actúan y se controlan los poderes, la rendición de cuentas a la sociedad y la sanción a los responsables. En ello radica la importancia de los controles que, como nos dice Manuel Aragón, "están orientados en un solo sentido, y todos responden a un único fin: fiscalizar la actividad del poder para evitar sus abusos". ${ }^{15}$ Cada uno de los poderes tiene que limitarse a lo que estrictamente le faculten la Constitución y los ordenamientos legales; la ley debe ser el freno del abuso del poder.

El control parlamentario es de carácter político y tiene por objeto vigilar la actuación del gobierno. En México corresponde al Congreso de la Unión, el cual, a su vez, puede presentar tres diversas manifestaciones: la primera, la instrumentación de medidas de control a través de decretos o leyes que establecen una normatividad tendente a regular específicamente los planes, el manejo de los recursos económicos, e inclusive la conducta de los servidores públicos. La segunda, que consiste en el control presupuestal, cuya facultad es exclusiva de la Cámara de Diputados, que abarca las dos grandes fases del presupuesto, es decir, la aprobación inicial y la de lo ejercitado como última fase del ejercicio financiero de los poderes, y una tercera, que se traduce en el control político, mismo que se ejerce a través de la facultad de exigir a los secretarios de Estado y titulares de organismos y empresas de participación estatal que comparezcan a informar sobre sus ramos, e incluso a través de la facultad de constituir comisiones especiales para investigar las actividades,

14 Garita Alonso, Miguel Ángel, Nuevo concepto de la división de poderes, México, UNAM, 2003, p. 15, disponible en: https://biblio.juridicas.unam.mx/bjv/detalle-libro /4146-nuevo-concepto-de-la-division-de-poderes (consultado el 12 de febrero de 2019).

15 Aragón, Manuel, Constitución, democracia..., cit., p. 97. 
los ejercicios presupuestales y el cumplimiento de programas por parte de cualquier ente que ejecute el gasto.

Solares Mendiola sostiene que “...cuando la dinámica de vigilancia mutua entre los poderes se ejerce de manera equilibrada y adecuada el resultado es un beneficio para toda la comunidad, pues su interés no estará en contradicción con el interés particular de quienes detentan alguno de esos poderes". ${ }^{16}$ Lo que se espera de un gobierno es que sus atribuciones se efectúen dentro de los límites que la Constitución y la legalidad les permita, y que sus políticas y programas redunden en un mejor nivel de vida para la población

Se puede afirmar que la división de poderes hace que cada poder se mantenga en sus límites y sirva de vigilante, contrapeso, freno y fiscalice a los otros. Dentro del principio clásico de la división de poderes se puede hablar de un control legislativo, administrativo y judicial o jurisdiccional, en los cuales se ordena al control en tres grandes rubros, que coinciden con los órganos constitutivos del Estado. Sin embargo, las funciones no se desarrollan en forma exclusiva por cada uno de los poderes, ya que en la práctica constitucional alguno de ellos indistintamente, dentro del marco de las leyes, puede no sólo ejercer la función que por su naturaleza se le encomiende, sino también alguna de los otros dos, tal es el caso del Ejecutivo, que emite observaciones a los proyectos de leyes o decretos, y, en su caso, los proyectos tienen que ser nuevamente analizados en las cámaras.

Al respecto, Valadés se pregunta si es posible controlar el poder; señala asimismo que controlar el poder contiene un enunciado en apariencia paradójico, y agrega:

La teoría newtoniana de los equilibrios inspiró el inteligente esquema de la separación de poderes. Uno de los efectos de esa relación es que los balances y contrapesos operan como fuerzas crecientes, no menguantes. En esa medida, y pensando en un sistema de equilibrios lo más cercano posible a lo ideal, tantas más atribuciones como se confieran a un órgano que ejerce funciones de poder, tantas más las que de manera agregada se irán incorporando progresivamente a otros órganos. ${ }^{17}$

16 Solares, Mendiola, Manuel, La Auditoría Superior de la Federación; antecedentes y perspectiva jurídica, México, UNAM, Instituto de Investigaciones Jurídicas, 2004, p. 123.

17 Valadés, Diego, El control del poder, 2a. ed., México, Porrúa, 2000, p. 56. 
Lo que se espera es que las funciones se encuentren expresamente determinadas y que cada uno de los poderes respete sus límites constitucionales, y en ello el Poder Judicial es el que a través de los medios de control constitucional limita a los poderes. En este tenor y siguiendo las opiniones anteriores, existe un proceso de vigilancia mutua del desarrollo de las funciones de los poderes; es decir, de controles recíprocos, de frenos y contrapesos. A saber, el Ejecutivo propone los montos de su presupuesto y el Legislativo lo aprueba, lo modifica o rechaza; el Senado aprueba al Ejecutivo la suscripción de tratados internacionales, también designa a los ministros de la Suprema Corte de Justicia de la Nación, de entre la terna que someta a su consideración el presidente de la República, o bien, la Cámara de Diputados les revisa la cuenta pública. Dicho control no sólo es de carácter jurídico, sino político, toda vez que son las fuerzas partidistas que integran la Cámara de Diputados las que deciden el sentido de los votos de los dictámenes; es evidente que los legisladores se subordinan a las indicaciones del coordinador.

Aragón Reyes considera al control parlamentario "como un control político, el cual en el estado constitucional, es un poder limitado; pero como no hay limitación sin control, poder limitado significa necesariamente, poder controlado". ${ }^{18}$ Asimismo, precisa que la definición más apropiada del mismo es la siguiente: "Es toda actividad parlamentaria orientada a comprobar, inspeccionar, registrar, analizar, revisar, intervenir y examinar la actividad del Ejecutivo". ${ }^{19}$ Lo anterior implica controlar la acción del gobierno; en este caso, el Poder Legislativo se constituye en un freno y contrapeso, no sólo en las preguntas, interpelaciones, comisiones de investigación, sino también en el proceso legislativo y en los actos de aprobación o autorización, de nombramientos o de elección de personas, etcétera. En todos los casos hay o puede haber control, y todos esos instrumentos, si no características, son, desde luego, instrumentos a través de los cuales opera el control parlamentario.

Como parte del control parlamentario se encuentra el control del gasto, que impide el ejercicio ilimitado o abusivo de los recursos por parte de los servidores públicos; como mencionamos previamente, es una facultad exclusiva de la Cámara de Diputados, a través de una serie de actividades para vigilar, cuestionar y frenar los actos del gobierno, lo cual también es una característica de los regímenes democráticos. El control del gasto público

\footnotetext{
18 Aragón, Manuel, Constitución, democracia..., cit., p. 247.

19 Idem.
} 
lo efectúa la Cámara de Diputados a través de la Auditoría Superior de la Federación, su órgano técnico.

Cecilia Mora sostiene que el control parlamentario es un control de carácter político cuyo agente es el Parlamento y cuyo objeto es la acción general del gobierno y, por extensión, también la acción de toda entidad pública. Excluye del control parlamentario al Poder Judicial, y señala que por principio "es un poder que goza de total independencia respecto de los demás poderes del Estado". ${ }^{20}$ Efectivamente, no obstante, en materia de control del gasto, el Poder Legislativo, a través de la Cámara de Diputados, también ejerce control sobre el Poder Judicial, cuando interviene en la designación de sus integrantes, aprueba su presupuesto y fiscaliza su ejercicio mediante la revisión de la cuenta pública.

\section{CONTROL EXTERNO}

El control de las finanzas públicas se configura como un derecho de los ciudadanos en el artículo 14 de la Declaración de los Derechos del Hombre y del Ciudadano de $1789^{21}$ ("los ciudadanos tienen derecho a verificar por sí mismos o por medio de sus representantes la necesidad de la contribución pública, de consentirla libremente, de controlar su empleo y determinar las cuotas, la base tributaria, la recaudación y la duración de dicha contribución"); a su vez, en el artículo 16 se incorpora el principio de la división de poderes (la sociedad en donde no estén garantizados los derechos ni esté establecida la separación de los poderes carece de Constitución).

La etimología de la palabra "control" proviene del término latino-fiscal medieval contra rotulum, y de ahí pasó al francés contre role (controle), que

20 Mora-Donatto, Cecilia, "Instrumentos constitucionales para el control parlamentario", Cuestiones Constitucionales. Revista Mexicana de Derecho Constitucional, México, núm. 4, enero-junio de 2001, disponible en: https://revistas.juridicas.unam.mx/ index.php/ cuestionesconstitucionales/article/view/5611/7306 (consultado el 12 febrero de 2019).

21 Conviene destacar el contenido de la Declaración Universal de los Derechos del Hombre y del Ciudadano de 1789 que expresa: "los representantes del pueblo francés, constituidos en Asamblea Nacional, considerando que la ignorancia, el olvido o el menosprecio de los derechos del hombre son las únicas causas de las calamidades públicas y de la corrupción de los gobiernos, han resuelto exponer, en una declaración solemne, los derechos naturales, inalienables y sagrados del hombre"; Instrumentos internacionales de derechos humanos, disponible en: http://www.juridicas.unam.mx/publica/librev/ rev/derhum/cont/30/pr/pr23.pdf(última fecha de consulta: 19 de octubre de 2018). 
significa literalmente "contra libro", es decir, "libro registro", que permite contrastar la veracidad de los asientos realizados en otros; dicho término se generalizó poco a poco hasta ampliar su significado al de "fiscalizar", "someter", "dominar", etcétera. ${ }^{22}$

El vocablo "control" se encuentra en casi todos los idiomas. Manuel Aragón señala que el término control en inglés se refiere a "dominio", a diferencia de lo que ocurre en francés, en el que el término más bien se restringe a "comprobación"; en alemán (kontrolle) significa "comprobación", "registro", "vigilancia", pero también "intervención", "dominio" y "revisión”; en italiano (controllo), "revisión", "inspección", "verificación”, pero también "vigilancia, "freno" y "mando". ${ }^{23}$ Afirma que el Diccionario de la Real Academia Española recoge los dos orígenes de la palabra "control", señalando que es un galicismo y un anglicismo, con lo cual se pueden utilizar ambas acepciones, posibilitándose así la existencia del control por el Parlamento y control en el Parlamento. El término "control parlamentario" en el idioma español significa principalmente la comprobación, inspección, análisis, registro, revisión, intervención o examen que realiza el Parlamento sobre la actividad, ya sea positiva o negativa, del gobierno, cuyas características son, sobre todo, la discusión, publicidad e influencia en la opinión pública, teniendo así una dimensión política para considerarlo como control político parlamentario.

Como se aprecia, el término "control", en la mayoría de los idiomas, involucra la comprobación, inspección, análisis, revisión o examen. Dichos vocablos se adoptan en nuestra Constitución federal, al señalar, en el artículo 74, los términos "revisar", "evaluar", "examinar" y "fiscalizar".

Si nos avocamos al control externo, Vanossi señala que dado que quien ejerce el poder no se controla a sí mismo, es indispensable la independencia del órgano controlante respecto de aquel que es controlado. Si existe subordinación estimamos que es muy probable que exista sometimiento; es necesaria la independencia de las instituciones que rinden cuentas para que el control sea eficaz. Añade que es necesario precisar cuál va a ser el ámbito de lo controlado, pues quien ejerce el poder puede ser sometido, según sean las funciones controlables, a un control político o a un control jurídico. ${ }^{24}$

\footnotetext{
22 Castillo Garrido, Salvador, Los jueces de control en el sistema acusatorio en México, UNAM, Instituto de Investigaciones Jurídicas, 2012, pp. 51 y 52

23 Aragón, Manuel, Constitución, democracia..., cit., p. 121.

24 Vanossi, Jorge, El Estado de derecho en el constitucionalismo social, Buenos Aires, Eudeba, 1982, p. 92.
} 
Precisamente una característica esencial del control externo en México es que se ejerce por un poder a otro; es decir, poderes independientes que se frenan unos a otros, concretamente el Poder Legislativo a los poderes Ejecutivo y Judicial, cuando les fiscaliza el ejercicio del gasto público. Es importante destacar que la Organización Internacional de Entidades Fiscalizadoras Superiores (INTOSAI, por sus siglas en inglés) en la Declaración de Lima sobre las Líneas Básicas de Fiscalización ${ }^{25}$ establece que las entidades fiscalizadoras superiores sólo pueden llevar a cabo sus cometidos si son independientes de la institución fiscalizada y están protegidas contra influencias externas.

Madariaga hace referencia al control externo o fiscalización, señalando que se encomienda a las contadurías mayores o tribunales de cuentas y que se encarga a entidades que conforman la administración fiscalizadora, dotadas de autonomía e independencia. ${ }^{26}$ Como fiscalizadores externos se encuentran los tribunales de cuentas, que son órganos con independencia funcional y realizan una función jurisdiccional, poseen atribuciones para revisar las cuentas generales y establecer la denominada responsabilidad contable o resarcitoria a cargo de los servidores públicos encargados del manejo de caudales públicos, cuando hagan un mal uso de los mismos, como el caso de España. ${ }^{27}$ Yolanda Gómez afirma que el carácter externo de la fiscalización que realiza el Tribunal de Cuentas confirma igualmente

25 Declaración de Lima sobre las Líneas Básicas de Fiscalización, Perú, Organización Internacional de Entidades Fiscalizadoras Superiores, octubre de 1977, disponible en: http://www.intosai.org/fileadmin/downloads/downloads/0_news/2017/061217_forty years_lima_SP_commemorative.pdf (consultada el 12 de febrero de 2019).

26 Madariaga Gutiérrez, Mónica, Seguridad jurídica y administración pública en el siglo XXI, 2a. ed., Chile, Editorial Jurídica de Chile, 1993, p. 74.

27 En los regímenes constitucionales de diversos países existen distintos modelos de tribunales de cuentas, según que éstos sean órganos colegiados o unipersonales (caso de Inglaterra o Canadá), tengan o no tengan atribuidas funciones jurisdiccionales (caso de Alemania) o consultivas (con las que cuentan Alemania, Holanda o Luxemburgo), dependan del Poder Legislativo o auxilien al Ejecutivo (Francia o Italia). El propio Tribunal de Cuentas de las Comunidades Europeas, elevado a rango de "Institución comunitaria" mediante el Tratado de la Unión Europea, no depende de ninguna otra institución (asiste al Parlamento europeo y al Consejo en el ejercicio de su función de control en la ejecución del presupuesto, pero no depende de ninguno de ellos) y ejerce funciones fiscalizadoras y consultivas, pero no jurisdiccionales. Dentro del derecho interno español, también los órganos de control con que cuentan las comunidades autónomas ofrecen perfiles variados entre sí y respecto del Tribunal de Cuentas, pues carecen de competencias jurisdiccionales. 
su independencia frente a todos los demás órganos o instancias sometidas a su control. ${ }^{28}$

El control externo comprende

...el conjunto de procedimientos, medidas y métodos coordinados, aplicados por el Organismo Superior de Control y por las sociedades o firmas privadas de auditoría debidamente, con el fin de: 1) verificar, evaluar y dar fe sobre la situación financiera, los resultados de las operaciones, el cumplimiento de las disposiciones legales y el logro de las metas y objetivos programados con el máximo grado de eficiencia, efectividad y economía en la utilización y salvaguardia de los recursos humanos, materiales y financieros, 2) emitir recomendaciones para mejorar las operaciones, actividades y transacciones que se consideren necesarias. ${ }^{29}$

De esta definición se puede desprender que el control externo moderno es siempre posterior; esto es, una vez ejercido el gasto público, y como se emplean técnicas modernas de auditoría, es muy diferente del control interno, que en sus aspectos previos y concurrentes está integrado en los procesos administrativos, lo cual implica que pueden revisarse los procesos de asignación de recursos públicos y su ejercicio durante el año fiscal, aunado a que el órgano encargado de ejercerlo depende jerárquicamente de quien le encomienda la revisión, tal es el caso de la Secretaría de la Función Pública, que en México es la dependencia del Ejecutivo Federal encargada del control interno. ${ }^{30}$ Yolanda Gómez distingue entre control interno y control externo, al señalar, en el primer caso, que el órgano de control está integrado en el órgano controlado, mientras que en el control externo, el sujeto que lleva a cabo la fiscalización es independiente del controlado. ${ }^{31}$

28 Gómez Sánchez, Yolanda, El tribunal de cuentas, el control económico-financiero externo en el ordenamiento constitucional español, Madrid, UNED-Marcial Pons, Ediciones Jurídicas y Sociales, 2001, p. 173.

29 Manual latinoamericano de auditoría profesional en el sector público, Instituto Latinoamericano de Ciencias Fiscalizadoras, 1977, p. 114.

30 El control interno que realiza la Secretaría de la Función Pública tiene carácter preventivo y su característica esencial es que se efectúa durante el ejercicio del gasto, en teoría para corregir desviaciones. Es de hacer notar que en cada una de las secretarías de estado se asigna a un representante de esta dependencia del Poder Ejecutivo, como titulares de los órganos internos de control.

31 Gómez, Yolanda, El tribunal de cuentas..., cit., p. 173. 
Nos dice Valadés que un denominador común de los Estados constitucionales es el control eficiente del poder para garantizar el espacio de libertades individuales y colectivas, y la equidad entre los miembros de la colectividad. ${ }^{32}$ Se refiere al control de los recursos públicos de la siguiente forma:

Un control eficiente buscará que los actos del gobierno se apeguen al marco jurídico y que se realice en términos de economía, eficacia, eficiencia, rendimiento y productividad. En primer término el control tiene como objetivo la vigilancia y fiscalización del uso correcto de los recursos humanos, materiales y financieros de que se dispongan para el cumplimiento de los programas, lo cual involucra una debida planeación, programación y evaluación; así como, aplicando medidas correctivas de manera que la ejecución se lleve a cabo de acuerdo con lo planeado. ${ }^{33}$

Valadés se refiere en este aspecto al control del gasto y a su uso racional, e introduce en su análisis conceptos como economía, eficacia, eficiencia, rendimiento y productividad, que es lo que se espera de un gobierno cuando gasta las contribuciones y el presupuesto conformado por ellas. Adicionalmente, se refiere al cumplimiento de los programas y afirma que involucra una debida planeación, programación y evaluación, así como aplicación de medidas correctivas, de manera que la ejecución se lleve a cabo de acuerdo con lo planeado. No basta gastar correctamente un presupuesto, es decir, que en su ejecución se haya observado el marco legal aplicable, sino que es precisamente en la debida planeación y programación del gasto donde puede ser medido el desempeño de los gobiernos, considerando recursos, beneficiarios y sobre todo efectividad de las políticas públicas y programas, así como que se realice con eficiencia y eficacia.

Conviene destacar que para Yolanda Gómez, control de eficiencia se refiere a la adecuación entre el producto obtenido y su coste; el control de eficacia, de otra parte, se refiere a los efectos y coste de una determinada actividad en relación con unos objetivos previamente definidos. ${ }^{34}$

\footnotetext{
32 Valadés, Diego, El gobierno del gabinete, México, UNAM, Instituto de Investigaciones Jurídicas, 2003, p. 2.

33 Sobre este punto, véase Arellano Gault, David, Gestión estratégica para el sector público. Del pensamiento estratégico al cambio organizacional, México, Fondo de Cultura Económica, 2004, p. 14.

34 Gómez Sánchez, Yolanda, El tribunal de cuentas..., cit., p. 174.
} 
La sociedad exige que los recursos públicos sean ejercidos de forma adecuada. Los investigadores José Carbonell y Rodrigo Gutiérrez, al definir el concepto de democracia, afirman que presupone también elementos abstractos, tales como libertades de asociación y expresión, Estado de derecho, reconocimiento de derechos fundamentales, acceso a la información, rendición de cuentas, transparencia y eficacia en el ejercicio de las responsabilidades públicas y otros que impactan en las instituciones y políticas públicas del Estado. ${ }^{35}$

En términos de la Normatividad para la Fiscalización Superior, la eficacia implica que los servidores públicos ejerzan el presupuesto de acuerdo con lo planeado; deben cumplir los objetivos y metas programáticos con los recursos disponibles y en los plazos previamente establecidos. También se espera que los recursos se apliquen racionalmente; que el gasto empleado sea para obtener el beneficio esperado y la capacidad para garantizar la consecución de los objetivos y metas de los programas y proyectos. ${ }^{36}$ Los servidores públicos deben usar racionalmente los medios con que se cuenta para alcanzar un objetivo predeterminado y evitar dispendios o errores; en suma, deben administrar el gasto público con economía, transparencia y honradez.

El artículo 134 constitucional obliga a que los recursos económicos de la Federación, las entidades federativas, los municipios y las demarcaciones territoriales de la Ciudad de México se administren con eficiencia, eficacia, economía, transparencia y honradez para satisfacer los objetivos a los que estén destinados. Asimismo, para que los resultados del ejercicio de dichos recursos sean evaluados por las instancias técnicas que establezcan, respectivamente, la Federación y las entidades federativas; esto es, a entidades de fiscalización superior.

Actualmente, en México, la Auditoría Superior de la Federación practica evaluaciones respecto del desempeño a los auditados, lo cual supera el mero análisis financiero del ejercicio del gasto, es decir, si se encuentra justificado y comprobado, sino que va más allá, al analizar si la planeación y programación del gasto fue adecuada; para ello, verifica la eficiencia, la

35 Carbonell, José y Gutiérrez, Rodrigo, Enciclopedia jurídica mexicana, México, Porrúa-UNAM, Instituto de Investigaciones Jurídicas, 2004, t. III, voz "Democracia”, pp. 131-137.

36 Normativa para la fiscalización superior, marco rector. Normas y esquema operativo, Auditoría Superior de la Federación, noviembre de 2011, disponible en: http://www. oas.org/juridico/pdfs/mesicic4_mex_asf_norm.pdf(consultado el 12 de febrero de 2019). 
eficacia y la economía con que se desarrollan los programas y su efecto o la consecuencia en las condiciones sociales, económicas y, en su caso, regionales del país durante el periodo que se evalúa. En este aspecto ha elaborado una serie de indicadores, en los cuales incluso se mide el impacto de los programas, a través de encuestas de percepción que se realizan a la población objetivo de los programas.

Sin embargo, debemos considerar que la revisión de la Auditoría Superior de la Federación es posterior al ejercicio del gasto, porque el control que ejerce es externo o posterior, $y$, en consecuencia, los errores o desvíos en la planeación y programación del gasto se detectan cuando ha transcurrido el ejercicio fiscal. ${ }^{37}$ Por ello, en diversas recomendaciones ha insistido a los órganos internos de control la importancia de la autocorrección, que se realiza durante el ejercicio del presupuesto. Si se detecta una irregularidad por el órgano interno de control de un ente público, podrá prevenir o aminorar los daños económicos o evitar su recurrencia.

Vázquez Alfaro señala que el control de la administración pública se lleva a cabo por órganos independientes dotados de autonomía técnica y de facultades para supervisar y vigilar las materias administrativa y financiera, y que el objetivo principal de esta clase de control es obligar a la administración a respetar las normas jurídicas, por lo que constituyen un complemento al autocontrol. ${ }^{38}$ Es decir, distingue del control interno, que denomina "autocontrol", y que se ejerce por la propia administración, del control externo que efectúa la Auditoría Superior de la Federación.

En relación con lo anterior, algunos autores clasifican al control como $a$ priori o preventivo y a posteriori o ex post, que se realiza cuando los actos se han ejecutado totalmente, tal es el caso de la revisión de la cuenta pública, que se efectúa por los gobiernos una vez que se ha concluido el ejercicio del presupuesto. En este orden de ideas, el control a priori es el interno, y el $a$ posteriori es el externo; sin embargo, la característica esencial se determina por el momento en que se efectúa la revisión.

37 Con motivo de la reforma anticorrupción de 2015, la Auditoría Superior de la Federación se encuentra facultada para solicitar y revisar, de manera casuística y concreta, información de ejercicios anteriores al de la cuenta pública en revisión, exclusivamente cuando el programa, proyecto o la erogación, contenidos en el presupuesto en revisión, abarque para su ejecución y pago diversos ejercicios fiscales o se trate de revisiones sobre el cumplimiento de los objetivos de los programas federales.

38 Vázquez Alfaro, José Luis, El control de la administración pública en México, UNAM, Instituto de Investigaciones Jurídicas, 1996, pp. 19 y 20. 
Faya Viesca refiere que el control es el mecanismo para verificar y asegurarse que las finanzas públicas se han llevado a cabo de conformidad con las normas establecidas. ${ }^{39} \mathrm{El}$ control financiero se orienta, en consecuencia, a certificar si la gestión financiera se llevó a cabo de acuerdo con las leyes y reglamentos aplicables tanto en el caso de un control a priori como en el caso de un a posteriori o ex post. Otra de las finalidades del control es constatar si la gestión ha sido adecuada, y en el caso de un control de calidad, tratará de comprobar si la gestión ha mejorado a través de una revisión continuada de los métodos, procedimientos y estructuras.

Como ya hemos mencionado, el control también comprende el desempeño de la administración, mediante revisiones a los resultados del ejercicio del presupuesto, así como el impacto de los programas en la población, a través de encuestas aplicadas directamente a los ciudadanos para medir su percepción respecto a los programas gubernamentales, o a través de índices que se elaboran por instituciones especializadas, como los relativos a la pobreza, a la violencia, o a la incidencia delictiva.

El control tiene como finalidad examinar la racionalidad económica de una política financiera, Faya Viesca afirma que en México el control del presupuesto se orienta a constatar que el Poder Ejecutivo esté cumpliendo con la decisión de la Cámara de Diputados en materia presupuestaria. Si el Poder Ejecutivo se aparta de las autorizaciones presupuestarias de la Cámara, fundamentalmente estaría violando una decisión netamente política. La segunda finalidad de control del presupuesto es financiera, en la cual se trata de vigilar e impedir acciones presupuestarias de carácter dispendiosas, de desorden y corrupción; además, tiene la finalidad de cuidar no sólo la exacta y adecuada aplicación del gasto, sino también verificar el cumplimiento de los programas consignados en el presupuesto. ${ }^{40}$

El objetivo del control recae, como consecuencia y en cualquier caso, sobre la detección o la prevención de deficiencias o irregularidades en el desarrollo de la actividad financiera estatal, porque es lógico aspirar a un sistema de control equilibrado en el cual estén inmersos todos los aspectos.

La fiscalización de las cuentas públicas que realiza la Auditoría Superior de la Federación no sólo se concreta a verificar si el presupuesto se ejerció de acuerdo con los montos autorizados, si no que incluye diversas revisiones de carácter legal, contable, económica, financiera, programáticas y de gestión, así como de desempeño.

\footnotetext{
39 Faya Viesca, Jacinto, Finanzas públicas, 3a. ed., México, Porrúa, 1996, p. 272.

40 Ibidem, p. 273.
} 


\section{LA RENDICIÓN DE CUENTAS}

La democracia es una forma de gobierno en la que los gobernantes son completamente responsables ante los gobernados, por lo que aquellos que ejercen el poder están obligados a rendir cuentas de sus acciones a los ciudadanos.

La rendición de cuentas y la fiscalización del uso de los recursos públicos son elementos fundamentales de las democracias modernas. En dicho sistema se aspira a un gobierno honesto y respetuoso de la legalidad. Por ello, resulta indispensable el cumplimiento de los procesos de control del ejercicio del gasto público y el apego al principio de rendición de cuentas, los cuales se encuentran íntimamente ligados.

Ugalde señala que en ocasiones "control" y "fiscalización" son mecanismos para supervisar los actos de gobierno, pero no siempre implican la obligación de los gobernantes para informar de manera periódica sobre sus decisiones y acciones. Por ello, el control y la fiscalización son mecanismos de un sistema global de rendición de cuentas, pero éste abarca además otros instrumentos, como la transparencia y los informes que los gobernantes deben rendir a los ciudadanos. ${ }^{41}$

El concepto se liga a la voz sajona accountability, que significa responsabilidad, relacionado con accountable, que en uno de sus significados hace referencia a rendir cuentas. También se traduce como "el estado de ser sujeto a la obligación de reportar, explicar o justificar algo, ... ser responsable de algo (liable)... ser sujeto y responsable de dar cuentas y responder preguntas (answerable)". ${ }^{42}$

La rendición de cuentas involucra necesariamente el apego a la legalidad de los servidores públicos, la obligación de informar a la población respecto del desarrollo de sus funciones y la posibilidad de ser sancionado si se apartó del cumplimiento de disposiciones legales que rigen su actuación o el manejo y administración de fondos públicos. Como bien afirma Shedler, la rendición de cuentas incluye, por un lado, la obligación de políticos y funcionarios de informar sobre sus decisiones y de justificarlas en público. Por otro, incluye la capacidad de sancionar a políticos y funcionarios. ${ }^{43}$

41 Ugalde, Luis Carlos, Rendición de cuentas y democracia: el caso de México, México, Instituto Federal Electoral, 2002, p. 10.

42 Ibidem, p. 11.

43 Shedler, Andreas, ¿Qué es la rendición de cuentas?, México, IFAI, 2004, p. 11. 
López Ayllón y Merino afirman que la rendición de cuentas es siempre una acción subsidiaria de una responsabilidad previa, que implica una relación transitiva y que atañe a la manera en que se dio cumplimiento a esa responsabilidad. Es subsidiaria en el sentido de que una acción o responsabilidad robustece a otra principal, y por ello carece de todo sentido si es un acto único y aislado de cualquier precedente, y es transitiva en tanto que hay al menos dos sujetos que participan en el proceso de rendición de cuentas con roles distintos, y aunque parezca obvio, es preciso tener presente que esa relación perdería todo sentido si aquellos que rinden cuentas no están obligados, no se someten a los juicios y no acatan los resultados de las sanciones impuestas de aquellos ante quienes se rinden cuentas y de ahí afirman que la rendición de cuentas es un antídoto contra la impunidad. ${ }^{44}$

Como se aprecia, existe coincidencia en que la rendición de cuentas implica la obligación de informar sobre el cumplimiento de una responsabilidad y la posible sanción en caso de apartarse de dicha responsabilidad; este último supuesto es vital para no propiciar la impunidad.

Coincidimos con José Antonio Crespo cuando señala que "rendir cuentas supone la capacidad de las instituciones políticas para hacer responsables a los gobernantes de sus actos y decisiones, en los distintos niveles de poder. Eso permite, dentro de lo posible, evitar, prevenir y, en su caso, castigar el abuso de poder". ${ }^{45} \mathrm{El}$ principio de la rendición de cuentas busca conciliar el interés colectivo con el interés particular de los gobernantes. Si los gobernantes, servidores públicos, representantes y líderes políticos, es decir, todos los que dispongan de algún poder político, saben que pueden ser llamados a cuentas, que su acción política, su desempeño gubernamental y sus decisiones podrán, en su caso, ser sancionadas, tendrán mucho mayor cuidado en el momento de ejercer el poder, y atenderán tanto el interés colectivo como la relación de medios y fines en el quehacer gubernamental, precisamente para que el resultado de sus resoluciones no afecte o perjudique el interés general, o el particular de sus gobernados y representados.

Desde el punto de vista formal y teórico, la rendición de cuentas ha sido definida de diversas formas; el politólogo Karl Deutsch se refiere al comportamiento de un actor con controlador ante quien es responsable.

44 López Ayllón, Sergio, "La rendición de cuentas en México, perspectivas y retos", en La estructura de la rendición de cuentas en México, México, UNAM, Instituto de Investigaciones Jurídicas, 2010, p. 2.

45 Crespo, José Antonio, Fundamentos políticos de la rendición de cuentas, México, Auditoría Superior de la Federación, 2001, p. 7. 
El controlador puede recompensar o castigar considerando las acciones u omisiones. ${ }^{46}$

En materia de fiscalización superior, si derivado de una revisión la Auditoría Superior de la Federación detecta irregularidades en la revisión de las cuentas públicas, promueve una serie de acciones legales para, en su caso, evitar que esa irregularidad persista; recupere recursos públicos pagados de forma indebida y sancione administrativa o penalmente a los servidores públicos; no existen recompensas porque el servidor público es responsable de su actuación, la cual invariablemente debe estar apegada a la legalidad. Por ello, el control externo tiene que modernizarse a través de diversos procesos para detectar oportunamente a servidores públicos ineficientes para manejar los negocios públicos, y removerlos. En este aspecto tendría que ser el órgano técnico el que informe a través de sus evaluaciones de desempeño que la actuación es ineficiente; se trata de la llamada "responsabilidad política", y en ella incluimos a los servidores públicos que deciden políticas públicas; es decir, de niveles superiores de responsabilidad.

La rendición de cuentas supone, pues, que un gobernante en cualquier nivel de gobierno podrá ser sujeto de responsabilidad política — removido del poder - o responsabilidad legal — castigado administrativa o penalmente- - De esa forma, al saber el servidor público que puede ser removido o sancionado, tendrá mayor cuidado de no tomar malas decisiones o incurrir en abuso de poder por su propia conveniencia; no necesariamente pensando en el bienestar de sus gobernados, tendrá interés en conservar su prestigio profesional, su empleo, o bien un futuro cargo político. Sobre esta doble responsabilidad de los gobernantes - la honestidad y la eficacia — decían los padres fundadores de la democracia norteamericana: "Un buen gobierno implica dos cosas: primero, fidelidad a su objeto, que es la felicidad del pueblo; segundo, un conocimiento de los medios que permitan alcanzar mejor ese objeto". ${ }^{47}$ Ahí están sintetizados los tipos de responsabilidad gubernamental de que hemos hablado: la legal, relativa a la honestidad, y la política, asociada a la eficacia.

En materia de control, actualmente no basta que se compruebe que el gasto se efectúo en apego a la normatividad que regule el acto, o cuente con

\footnotetext{
46 Deutsch, Karl, Política y gobierno, México, Fondo de Cultura Económica, 1976, p. 220 .

47 Hamilton, Alexander, El federalista, México, Fondo de Cultura Económica, 6a. reimp., 1998, p. 264.
} 
facturas o comprobantes, sino que se requiere actualmente determinar que el ejercicio presupuestal trajo un beneficio a la población. En teoría, si los gobernantes observan que una política o programa no tiene los resultados esperados, éstas deben modificarse, si no se afecta doblemente a la población; por ello se requiere de un monitoreo y una programación adecuada para evaluar periódicamente los resultados, sin que la población tenga que asumir costos económicos porque los altos funcionarios no asumen la responsabilidad política. En este sentido, están obligados al monitoreo permanente del ejercicio del presupuesto, de los resultados e impacto de una política pública, del seguimiento de los programas, de establecer indicadores para medir permanentemente el desempeño, del seguimiento a las observaciones y recomendaciones emitidas por el órgano fiscalizador, así como las acciones para evitar su recurrencia.

Tanto el control interno como externo deben revisar de forma crítica y detallada los procesos para detectar o investigar actos u omisiones que impliquen alguna irregularidad o conducta ilícita. Se deben vigilar los procesos de atención al público, que es donde comúnmente se presentan actos de corrupción, pues con ello también se le combate.

Por ello, la rendición de cuentas públicas es fundamental, al grado en que puede establecerse de manera determinante que si las instituciones políticas no son capaces de llamar a cuentas a los gobernantes, de cualquier nivel, provoca la impunidad gubernamental. Y lo que se espera en las democracias es que al gobernante que viola las leyes se le sancione. A través del control externo se pueden determinar responsabilidades, e imponer multas y sanciones resarcitorias en los términos de la Ley. La Auditoría Superior de la Federación cuenta con facultades para determinar los daños y perjuicios que afecten a la hacienda pública federal o al patrimonio de los entes públicos federales, y para fincar directamente a los responsables las indemnizaciones y sanciones pecuniarias correspondientes, así como promover ante las autoridades competentes el fincamiento de otras responsabilidades. ${ }^{48}$

48 La Auditoría Superior de la Federación cuenta con facultades para promover acciones; es decir, instrumentos jurídicos para formular, promover, presentar o fincar ante la entidad fiscalizada o autoridad competente cuando los resultados de las auditorías presentan observaciones, lo cual incluye recomendaciones, recomendaciones al desempeño, solicitudes de aclaración, promociones de intervención de la instancia de control, promociones del ejercicio de la facultad de comprobación fiscal, pliegos de observaciones, promociones de responsabilidad administrativa sancionatoria, fincamiento de responsabilidad resarcitoria, denuncias de hechos y de juicio político. 
El sociólogo alemán Karl Popper define a la democracia en función de su capacidad institucional para llamar a cuentas a los gobernantes: "El nuevo problema ya no se formularía preguntando ¿quién debe gobernar?, sino mediante una pregunta muy diferente: ¿cómo debe estar constituido el Estado para que sea posible deshacerse de los malos gobernantes sin violencia y sin derramamiento de sangre?". ${ }^{49}$ No debemos olvidar que en diversos países el abuso del poder se ha frenado con revoluciones. Así pues, los mecanismos institucionales que permiten la rendición de cuentas son propios de la democracia y facilitan la remoción pacífica, e incluso la penalización de un mal gobernante con costos mínimos para la sociedad, y frenar a un gobernante para que no incurra en abuso de poder, todo lo cual eleva sustancialmente las probabilidades de que el interés particular de los gobernantes se concilie en algún grado importante con el bienestar colectivo de la sociedad, o al menos que no entren en franca contradicción, lo cual, como hemos mencionado, puede provocar una revolución o problemas de gobernabilidad.

Son muchos los mecanismos y procedimientos mediante los cuales una democracia estimula y favorece la rendición de cuentas. Justamente, las instituciones propias de la democracia tienen, entre sus funciones principales, las de coadyuvar coordinadamente a la rendición de cuentas de los gobernantes.

Desde una perspectiva distinta, John Ackerman ha propuesto entender a la rendición de cuentas como "un proceso proactivo por medio del cual los servidores públicos informan, explican y justifican sus planes de acción, su desempeño y sus logros y se sujetan a las sanciones y recompensas correspondientes..$^{50}$ Este concepto supone que la rendición de cuentas es un proceso dinámico y pro-activo, donde los servidores públicos salen a la calle a dialogar con la sociedad y con otras instituciones, Supone también entender que esos servidores están sujetos a sanciones tanto negativas (castigo) como positivas (recompensas).

Entonces, la rendición de cuentas implica necesariamente un marco jurídico y político, es decir, un marco de responsabilidad que se desprende a

49 Popper, Karl, "Un repaso de mi teoría de la democracia", Vuelta, n. 143, octubre de 1988, p. 11, disponible en: https://www.letraslibres.com/vuelta/un-repaso-mi-teoria-lademocracia (consultado el 12 de febrero de 2019).

50 Ackerman, John, "Social accountability for the public sector, A Conceptual Discussion”, Washington D. C., The Word Bank, 2005, en Ackerman, John (coord.), Más allá del acceso a la información, transparencia, rendición de cuentas y Estado de derecho, México, Siglo XXI, 2008, p. 16. 
la vez de obligaciones legales y públicas, bajo un principio de legalidad y con un propósito democrático.

López Ayllón explica lo anterior a través de un modelo en donde A es el obligado a rendir cuentas, $\mathrm{B}$ la autoridad y $\mathrm{C}$ alguien que tiene derechos fundamentales políticos y sociales, que puede ejercer en cualquier momento y por todas las vías jurídicas y políticas que tiene a su alcance, y podría traducirse en ciudadanos que otorgan calidad a la democracia, pero que resulta imprescindible para impedir que la relación entre A y B se justifique solamente a sí misma, de espaldas al espacio público democrático o, peor aún, que se convierta en una trampa democrática autoritaria; así, afirma:

Es la presencia de los ciudadanos, en el espacio público, la que permite hacer del proceso de rendición de cuentas una operación que va más allá del mero control del poder político sobre sus subordinados y sus burocracias. $\mathrm{Y}$ al mismo tiempo, es la que ofrece elementos de juicio para impedir la multiplicación, la fragmentación y la desconexión del sentido de la norma y los procedimientos de control y evaluación de la gestión pública y de sus resultados. ${ }^{51}$

Existen diversas actividades de gobierno que se vigilan por los ciudadanos, y en diversas ocasiones cuestionan la legalidad y eficacia de las decisiones tomadas y la responsabilidad de los servidores públicos.

De todo lo anterior se desprende que la Auditoría Superior de la Federación con los resultados de la revisión a la cuenta de la hacienda pública federal, debe posicionarse como una institución objetiva e imparcial, técnicamente sólida y sujeta a un proceso de mejora continua; sus resultados serán fundamentales para que la Cámara de Diputados asigne el presupuesto de egresos y contribuirá al combate a la corrupción. De esta manera, se podrá generar confianza en la población respecto al manejo de los recursos y a fortalecer una cultura gubernamental de transparencia y rendición de cuentas

\section{REFLEXIONES FINALES}

1. Un eficaz control del gasto público contribuye a la lucha contra la impunidad, la corrupción y la ilegalidad, y propicia el uso racional y eficiente

51 López Ayllón, Sergio, La rendición de cuentas..., cit., p. 7. 
del gasto público. Con reglas claras y transparentes, y un eficaz cumplimiento de la ley, se impedirá la corrupción del poder y se asegurará el funcionamiento de la democracia, como una forma de vida que verdaderamente busque un continuo mejoramiento de las condiciones económicas, sociales y culturales de los mexicanos.

2. El control externo, al evaluar el ejercicio presupuestal y cumplimiento de programas, propicia que la gestión pública se enfoque a asignar, de la manera más eficaz, los recursos financieros, humanos y tecnológicos disponibles para llevar a cabo acciones de impacto social que representen una diferencia real en la vida de los ciudadanos. El gobierno debe apegarse a los principios de transparencia y rendición de cuentas para contar con una hacienda pública sana; si las autoridades que ejercen el presupuesto público se apegan a los principios de legalidad, eficiencia y eficacia en el uso de los recursos y éstos se destinan a los fines para los que fueron autorizados, trae como consecuencia un mejor nivel de vida para los mexicanos.

3. El Poder Legislativo, al ejercer el control externo del ejercicio de los recursos públicos, debe impulsar la cultura de la legalidad, la transparencia, la honestidad y la eficiencia en el manejo de los recursos públicos.

4. Es necesario incluir a la eficacia, eficiencia y economía como elementos capitales en la gestión de los recursos públicos. Estos cambios deben hacerse patentes ante la percepción del ciudadano para que signifiquen un verdadero cambio cultural respecto a los asuntos públicos.

5. La rendición de cuentas es una tarea obligatoria; los funcionarios públicos deben entender y aceptar que tienen la obligación de rendir cuentas a la sociedad, porque manejan recursos que son de ella. En este sentido, es fundamental que la administración del Estado, en sus tres órdenes de gobierno, tengan mecanismos de fiscalización capaces de garantizar a los ciudadanos que los recursos públicos son utilizados conforme a su mandato y de manera honesta y transparente, y que los funcionarios públicos rindan cuentas, se hagan responsables de los actos ilícitos que cometan y estén, sin distinciones, sujetos a las sanciones que imponga la ley.

\section{BIBLIOGRAFÍA}

ACKERMAN, John (coord.), Más allá del acceso a la información, transparencia, rendición de cuentas y Estado de derecho, México, Siglo XXI, 2008. 
ARAGÓN, Manuel, Constitución, democracia y control, México, UNAM, Instituto de Investigaciones Jurídicas, 2002.

CARBOnell, José y GutiÉRREz, Rodrigo, Enciclopedia jurídica mexicana, México, Porrúa-UNAM, Instituto de Investigaciones Jurídicas, 2004, t. III.

CASTILlo GARRIDO, Salvador, Los jueces de control en el sistema acusatorio en México, México, UNAM, Instituto de Investigaciones Jurídicas, 2012.

CRESPO, José Antonio, Fundamentos politicos de la rendición de cuentas, México, Auditoría Superior de la Federación, 2001.

Declaración de Lima sobre las Líneas Básicas de la Fiscalización, Organización Internacional de las Entidades Fiscalizadoras Superiores (INTOSAI), Perú, 1997.

Deutsch, Karl, Política y gobierno, México, Fondo de Cultura Económica, 1976.

Estudio sobre las estrategias para enfrentar la corrupción, establecidas en las instituciones del sector público federal, México, Cámara de Diputados, Auditoría Superior de la Federación, diciembre de 2016.

FayA ViesCA, Jacinto, Finanzas públicas, 3a. ed., México, Porrúa, 1996.

Garita Alonso, Miguel Ángel, Nuevo concepto de la división de poderes, México, UNAM, 2003.

GómEZ SÁNCHEZ, Yolanda, El tribunal de cuentas, el control económicofinanciero externo en el ordenamiento constitucional español, Madrid, UNED-Marcial Pons-Ediciones Jurídicas y Sociales, 2001.

HAMilton, Alexander, El federalista, México, Fondo de Cultura Económica, 1998.

LANZ CÁRDENAS, José Trinidad, La contraloría y el control interno en México, 2a. ed., México, Secretaría de la Contraloría General de la Federación-Fondo de Cultura Económica, 1993.

LÓPEZ Ayllón, Sergio y Merino, Mauricio, La rendición de cuentas en México, perspectivas y retos, México, UNAM, Instituto de Investigaciones Jurídicas, 2010.

MAdAriaga GutiÉRreZ, Mónica, Seguridad jurídica y administración pública en el siglo XXI, 2a. ed., Chile, Editorial Jurídica de Chile, 1993.

Manual latinoamericano de auditoría profesional en el sector público, Instituto Latinoamericano de Ciencias Fiscalizadoras, 1977. 
MORA-DONATTO, Cecilia, "Instrumentos constitucionales para el control parlamentario", Cuestiones Constitucionales, Revista Mexicana de Derecho Constitucional, México, enero de 2001.

Normativa para la fiscalización superior, marco rector, normas y esquema operativo, Cámara de Diputados, Auditoría Superior de la Federación, 2011, t. I.

POPPER, Karl, “Un repaso de mi teoría de la democracia”, Vuelta, n. 143, octubre de 1988.

SHEDLER, Andreas, ¿Qué es la rendición de cuentas?, México, IFAI, 2004.

Solares, Mendiola, Manuel, La Auditoría Superior de la Federación; antecedentes y perspectiva jurídica, México, UNAM, Instituto de Investigaciones Jurídicas, 2004.

Ugalde, Luis Carlos, Rendición de cuentas y democracia: el caso de México, México, Instituto Federal Electoral, 2002.

VALADÉS, Diego, El control del poder, 2a. ed., México, Porrúa, 2000.

VALADÉs, Diego, El gobierno del gabinete, México, UNAM, Instituto de Investigaciones Jurídicas, 2003.

VANOSSI, Jorge, El Estado de derecho en el constitucionalismo social, Buenos Aires, Eudeba, 1982.

VÁZQUez Alfaro, José Luis, El control de la administración pública en México, México, UNAM, Instituto de Investigaciones Jurídicas, 1996.

Fecha de recepción: 10 de agosto de 2018.

Fecha de aceptación: 13 de febrero de 2019. 